\title{
The morbid anatomy of high altitude
}

\author{
Donald Heath \\ Ph.D., M.D., F.R.C.P., F.R.C.Path. \\ Department of Pathology, University of Liverpool, Liverpool L69 3BX
}

\section{Summary}

The morbid anatomical changes which take place in man and animals exposed to the chronic hypoxia of residence at high altitude are briefly reviewed.

Prolonged exposure to the chronic hypoxia of high altitude is associated with structural changes in many systems of the body. Such effects are developed to the greatest extent in native highlanders and they have been studied largely in the Quechua and Aymara peoples of the High Andes of Peru. This account is based on experience gained on four expeditions to the area around Cerro de Pasco in Central Peru at an altitude of $4000-4500 \mathrm{~m}$. The mining activity in this region sustains a sizeable Indian population which thus lives permanently at an elevation exceeding the summit of the Matterhorn.

The chemoreceptor system of the body has the specific function of monitoring the oxygen content of systemic arterial blood and one would assume that it would undergo changes in the face of a sustained stimulus of chronic hypoxaemia at high altitude. Such is indeed the case but the discovery that the carotid bodies enlarge in states of chronic hypoxia was made only a decade ago, pathologists before that time restricting their interest in the pathology of the carotid bodies to its tumour the chemodectoma. In 1969, Arias-Stella noticed that the carotid bodies of the Quechua Indians of the Peruvian Andes were larger than those of the mestizos living on the coast. Subsequently it was possible to show that the carotid bodies of guineapigs, rabbits and dogs from high altitude are larger than representatives of the same species at sea level (Edwards et al., 1971b). This investigation led the author and his colleagues to show that the carotid bodies of patients with chronic bronchitis and emphysema were also enlarged if there was associated hypoxaemia and right ventricular hypertrophy (Edwards, Heath and Harris, 1971a).

When the carotid bodies of animals enlarge rapidly on acute exposure to the hypoxia of simulated high altitude, the increase in size appears to be due simply to vascular congestion (Laidler and Kay, 1975) and under these circumstances it is not surprising that the enlargement of the carotid bodies is rapidly and largely reversible (Heath et al., 1973a). When the increase in size of the carotid bodies becomes chronic, however, owing to a persistent hypoxic stimulation, it has an organic basis of hyperplasia of chief (Type I) cells in the carotid bodies (Heath, Edwards and Harris, 1970). The sustentacular (Type II) cells do not appear to be involved in the enlargment. In cattle, the hyperplasia may become so extreme as to resemble the histological appearance of the tumour of the chemoreceptor tissues, the chemodectoma (Arias-Stella and Bustos, 1976). In man too it has now been established that the chemodectoma is much commoner at high altitude (Saldaña, Salem and Travezan, 1973).

The enlarged carotid bodies show characteristi ultrastructural changes. The author found that the neurosecretory vesicles in the chief cells of eupoxies guinea-pigs were composed of a dense, centrat osmiophilic core with a surrounding thin clear halo and an outer limiting membrane (Edwards, Heath and Harris, 1972). In high altitude guinea-pigs the vesicles enlarge and the central osmiophilic core becomes smaller, fainter and eccentric. The surrounding halo swells to something resembling a small vacuole (Edwards et al., 1972). The functional significance of these electron-microscopic changes is as yet not worked out precisely, although in a general way they are probably associated with the blunted response of chemoreceptors to hypoxia which is known to occur in native highlanders or in patients with cardio-pulmonary disease predisposing to chronic hypoxia (Heath and Williams, 1977).

Within the bronchi, bronchioles and alveolar walls of the lung are cells which resemble those of carotid body in containing neurosecretory vesicles (Fig. 1). The cytoplasm of these cells has a limited affinity for silver salts which has to be reinforced by the introduction of reducing agents in the staining method, such as the Grimelius technique, used to demonstrate them. Sometimes these isolated pulmonary argyrophil or Feyrter cells as they are called (Fig. 2) are grouped together to form neuroepithelial bodies (Fig. 3). It has been shown recently that in rabbits born and spending their entire lives at an altitude of over $4300 \mathrm{~m}$ there is an increase in number of 


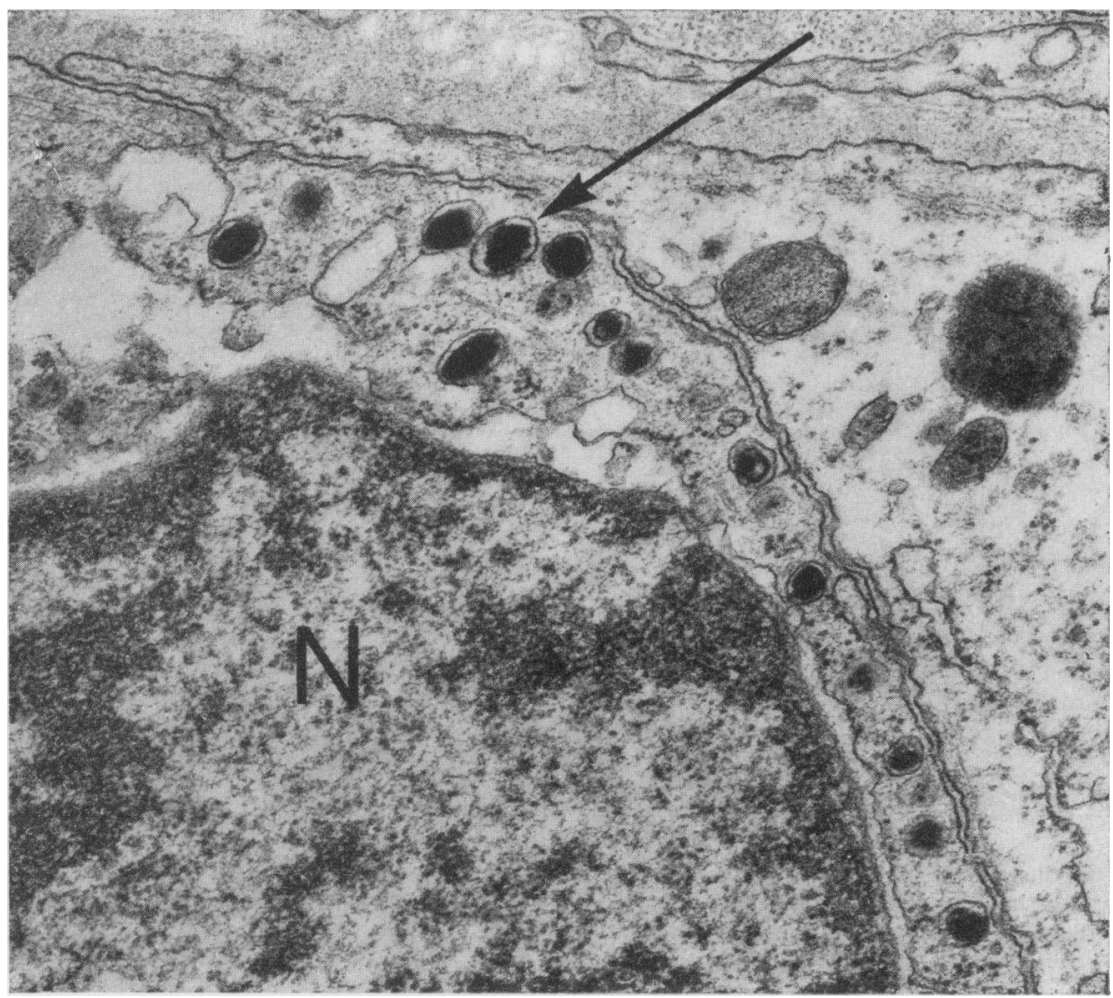

FIG. 1. Electron micrograph of one of a group of airway argyrophil cells from a sea-level rabbit. The cytoplasm contains dense-core secretory vesicles (arrow) the functional significance of which is at present obscure. Such cells have been reported as being increased in number in high-altitude rabbits. $N=$ nucleus $(\times 37,500)$.

neuroepithelial bodies in the airways and an increase in number of isolated argyrophil cells in the alveolar walls compared to sea-level control animals (Taylor, 1977). The function of this hyperplasia of pulmonary argyrophil cells at high altitude is at present obscure but it is tempting to speculate that they might act as airway chemoreceptors and increase in number in the same way as the chief cells of the carotid body respond to hypoxaemia. The author has ascertained that the dense-cored vesicles of Feyrter cells on exposure to hypoxia exhibit the same ultrastructural features that occur in the carotid bodies of guineapigs at high altitude (Moosavi, Smith and Heath, 1973).

The 2 main circulations of the body both respond to the chronic hypoxic stimulus inherent in residence at high altitude but interestingly enough the response of the pulmonary circulation is diametrically opposite to that of the systemic. Hypoxia is perhaps the most powerful pulmonary vasoconstrictor known (Harris and Heath, 1977), whereas it exerts a vasodilatory effect on the systemic vasculature.

In man, and other animal species which have to acclimatize to high altitude such as cattle, the chronic hypoxia of the mountain environment leads to muscularization of the terminal portions of the pulmonary arterial tree. At sea level the normal pulmonary arteriole, defined in man as having an external diameter of less than $100 \mu \mathrm{m}$, has a wall consisting of a single elastic lamina. It is unable to modify significantly the pulmonary vascular resistance to the flow of blood to the lung. At high altitude the pulmonary arteriole is muscularized so that it has a distinct media of circularly-orientated smooth muscle bounded by inner and outer elastic laminae (Fig. 4). On electron microscopy it can be seen that the external elastic lamina is thick and represents the original elastic lamina (Fig. 5). The layer of newly 


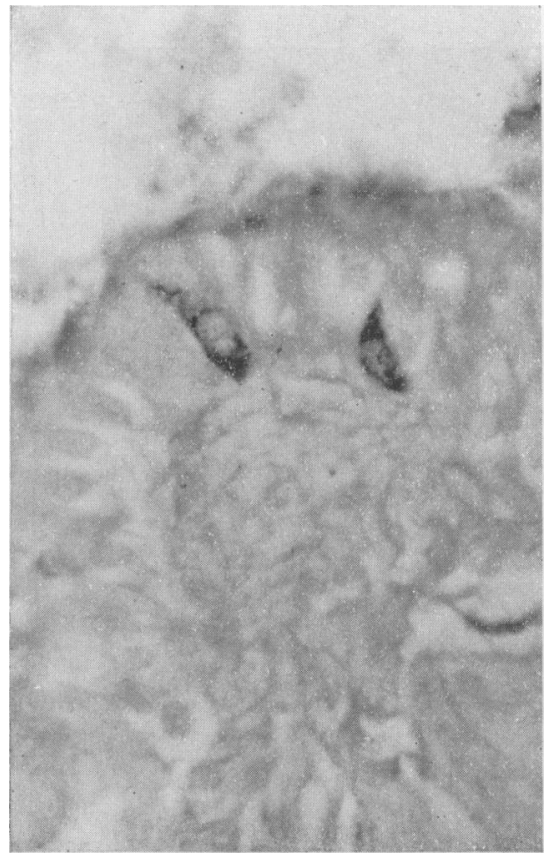

FIG. 2. Two spindle-shaped individual argyrophil cells in a bronchus of a sea-level rabbit. In rabbits native to high altitude there is an increase in number of such 'Feyrter cells' in the alveolar walls (Grimelius stain, $\times 600)$.

formed muscle arises internal to this and itself becomes bounded on the inner aspect by a new thinner, internal elastic lamina (Fig. 5). The pulmonary arteriole at high altitude resembles in appearance a systemic arteriole and, like it, it is able to constrict, elevate vascular resistance and restrict the flow of blood to the lung. As a result of this, native Quechua highlanders have a mild degree of pulmonary hypertension (Peñaloza et al., 1962). The level of the raised pulmonary arterial pressure is greater in children in whom the degree of muscularization of the pulmonary arterial tree is greater. The bovine pulmonary vasculature is naturally very muscular and as a result cattle are peculiarly susceptible to the vasoconstrictive effects of hypoxia on the lung. In calves grazing in the mountainous areas around Salt Lake City in the United States the strength of the pulmonary vascoconstriction may be such that the affected animals develop severe pulmonary hypertension which leads to congestive cardiac failure. This brings about pitting oedema in the region between the forelegs, the 'brisket' of commerce, and this clinical sign gives the disease its designation 'brisket disease' (Hecht et al., 1959). In striking

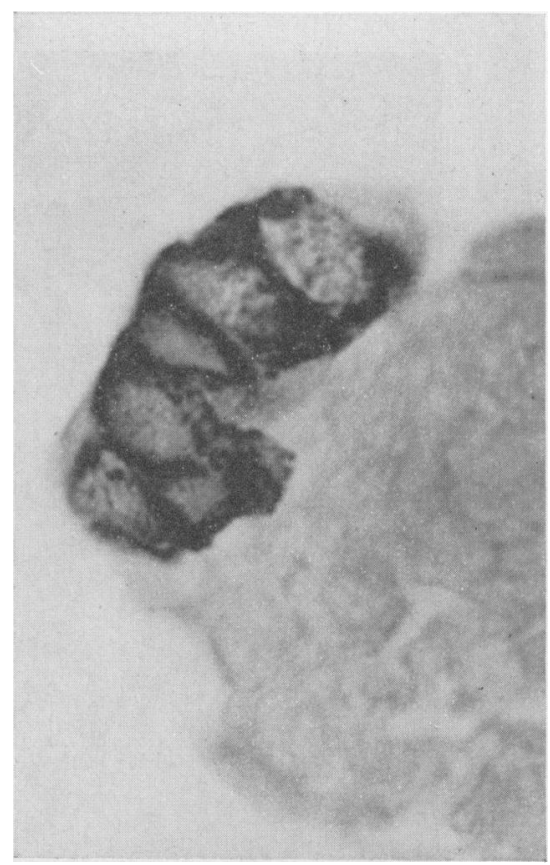

FIG. 3. A group of argyrophil cells in an alveolar wall in a sea-level rabbit. Rabbits born and bred at high altitude show increased numbers of such cell groups in the bronchi and bronchioles (Grimelius stain, $\times 1500$ ).

contrast, the pulmonary vasculature of the llama (Lama glama) appears to have lost its reactivity to hypoxia (Heath et al., 1974). As a result, there is no muscularization of pulmonary arterioles and right ventricular hypertrophy does not develop. This lack of vascular reactivity suggests that the llama adapts rather than, as man does, acclimatizes to high altitude. In passing it may be noted that the llama also lacks the other characteristic features of acclimatization seen in the Quechua. Thus its oxygenhaemoglobin dissociation is shifted to the left rather than to the right. It does not have elevated levels of 2,3-diphosphoglycerate and its haematocrit level is low (Heath and Williams, 1977).

The manner in which the chronic hypoxia of high altitude brings about pulmonary vasoconstriction and pulmonary hypertension is still obscure. For a long time it was tacitly accepted that alveolar hypoxia is a much more potent constrictor of pulmonary arteries than hypoxaemia, although this principle is no longer accepted without question. If one does accept the greater effectiveness of alveolar hypoxia in bringing about spasm of the terminal portions of the pulmonary tree, it suggests 


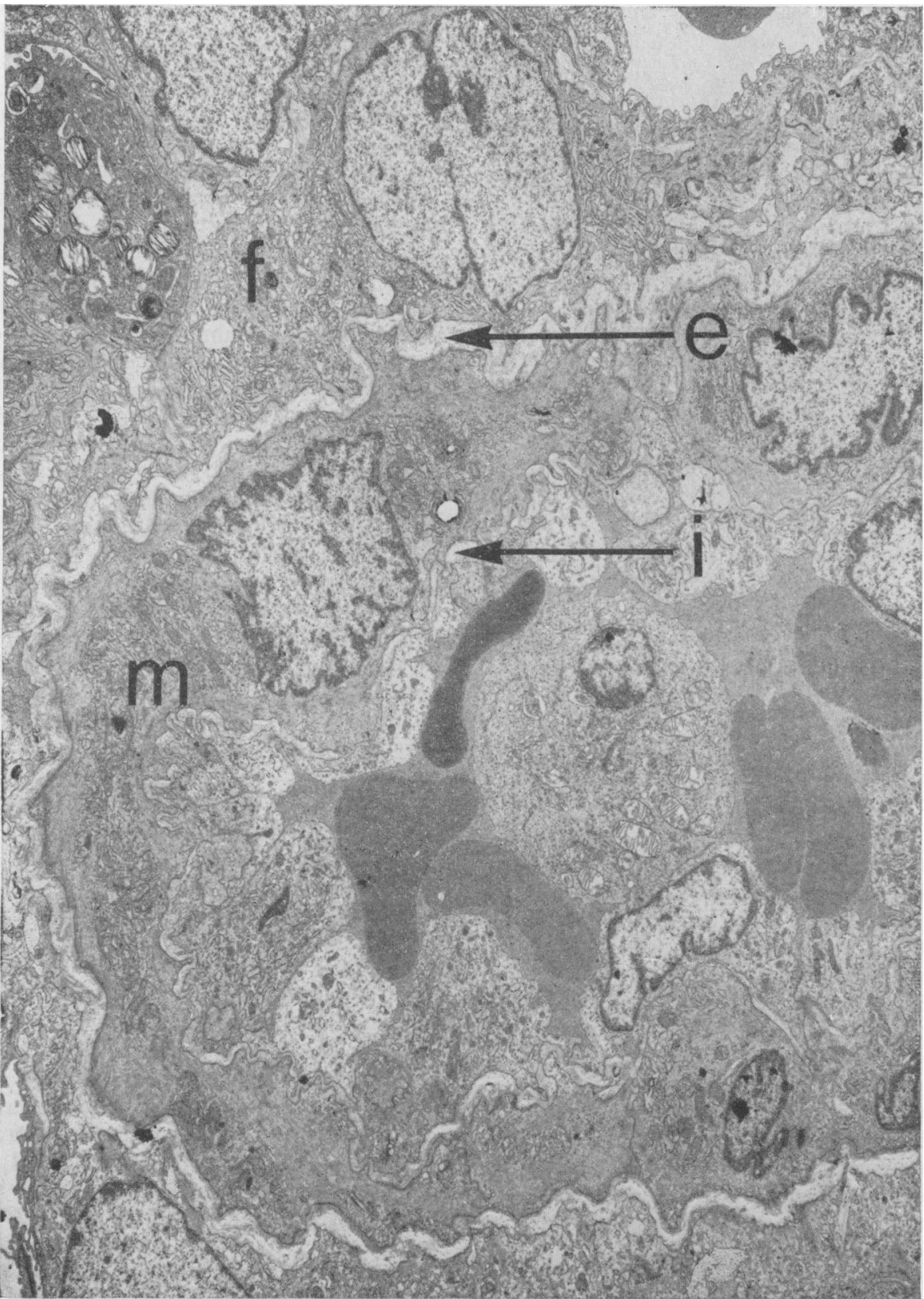

FIG. 5. Electron micrograph of a pulmonary arteriole in a rat subjected for 2 weeks to the hypoxia of a simulated altitude of $5500 \mathrm{~m}$ in a decompression chamber. There is muscularization so that new muscle cells, $\mathrm{m}$, have formed internally to the original elastic lamina, e. A thin internal elastic lamina, $i$, has formed over the inner aspect of the newly formed muscle coat. These ultrastructural features explain the appearance of a media sandwiched between 2 elastic laminae shown in Fig. 4. There is a fibroblast, $f$, in the adventitia $(\times 3750)$. 


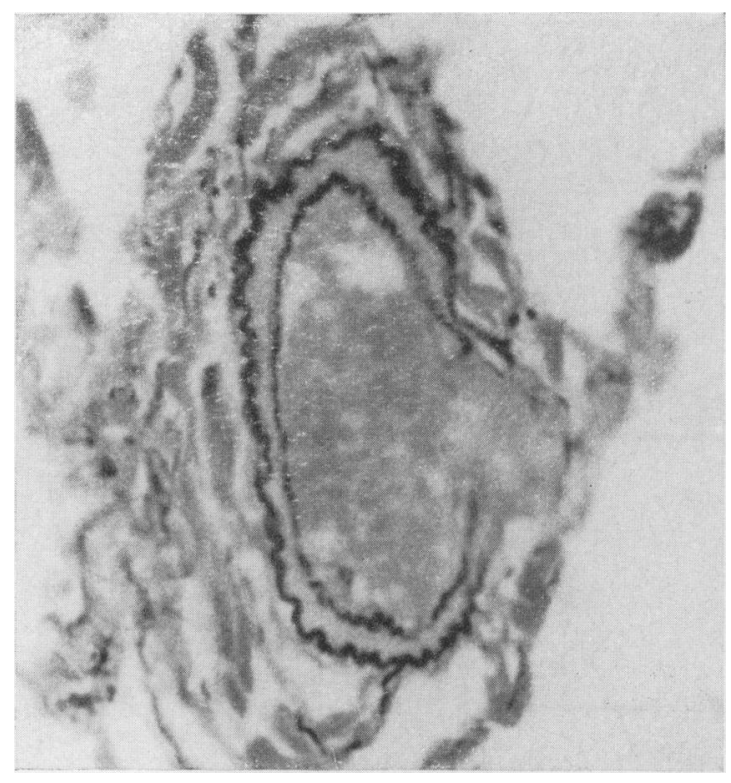

FIG. 4. Pulmonary arteriole from a Quechua Indian suffering from chronic mountain sickness (Monge's disease). This vessel differs from a normal pulmonary arteriole in having a distinct media of circular muscle sandwiched between inner and outer elastic laminae. It thus resembles a systemic arteriole and, like it, is capable of elevating pulmonary vascular resistance (Elastic van Gieson, $\times 275$ ).

that there is some cellular agent situated between alveolus and pulmonary arteriole capable of being stimulated by hypoxia and capable of secreting some substance bringing about constriction of muscularized arterioles. For a long time, the view of Haas and Bergofsky (1972) that the agent was the perivascular mast cell and the messenger was histamine was much favoured. This hypothesis has, however, now gone out of fashion and there is increasing suspicion that the hypoxia of high altitude exerts a direct action on the smooth muscle cell, perhaps with some system of biochemical amplification (Harris and Heath, 1977). There is evidence to suggest that in cattle at least there is a genetic predisposition to the development of pulmonary hypertension (Weir et al., 1974).

The pulmonary hypertension which characterizes the native highlanders is present from birth and this leads to structural effects in the walls of the large conducting elastic pulmonary arteries. At sea level the media of the pulmonary trunk in the fetus and newborn is as thick as that of the aorta and it has an elastic tissue configuration like that of the aorta (Heath et al., 1959). Thus the elastic fibrils of the pulmonary trunk are long, parallel and unbranched and this is a reflection of the fact that physiological pulmonary hypertension exists in the fetus. At birth at sea level, the pulmonary arterial pressure falls and the elastic fibrils of the media of the pulmonary trunk fragment into stick-like rods, the so-called transitional configuration. This form of disuse atrophy of the elastic tissue is well advanced by the age of 9 months and progresses so that by the end of the second year of post-natal life the elastic tissue of the pulmonary trunk has formed an open network of branched, irregularly-shaped elastic fibrils. This co-called 'adult pulmonary configuration' (Heath et al., 1959) is very characteristic of lowlanders. In those living at high altitude, however, the stimulus for the maintenance of a thick network of elastic fibrils in the media of the pulmonary trunk persists in the form of a hypoxic pulmonary hypertension. As a result, children in the high Andes exhibit the so-called 'persistent configuration' of elastica in which long, continuous, elastic fibrils reminiscent of those of the aortic media are admixed with fragmented elastic fibrils (Saldaña and Arias-Stella, 1963a). Thus, in the Peruvian Andes, children living in the altitude range $3440-3840 \mathrm{~m}$ show an aortic pattern of elastic tissue in their pulmonary trunks to the age of 3 years and this is followed by a persistent configuration which extends into middle age. In children living between 4040 and $4540 \mathrm{~m}$ the aortic configuration remains in the pulmonary trunk until the age of 9 years to be replaced by a persistent configuration of elastica which extends into middle age (Saldaña and Arias-Stella, 1963b). Thus the hypoxia of high altitude exerts a strong influence on the microanatomical structure of the pulmonary trunk. It is certainly true that man's very composition is dependent upon the partial pressure of oxygen in the air he breathes.

In contrast to its constricting effect on the pulmonary circulation, hypoxia has a relaxing effect on the smooth muscle of the systemic vasculature so that the effect on the arterial media is to produce vasodilatation. Hence the systemic blood pressure is lower in those living at high altitude than in sea level residents (Ruiz and Peñaloza, 1977). This fall in systemic blood-pressure is to found in native Quechua Highlanders in the Andes and in lowlanders like mining engineers who go to live in the mountains for a long period of time (Marticorena et al., 1969). Patients with systemic hypertension who live at high altitude for more than 2 or 3 years can be expected to show an amelioration in their level of systemic blood pressure provided the diastolic pressure does not exceed $95 \mathrm{mmHg}$.

It is commonly believed that high altitude 
pulmonary oedema is not associated with morphological abnormalities. The haemodynamic characteristics of this serious disorder are well known to be pulmonary arterial hypertension with normal pulmonary venous pressure (Fred et al., 1962). Any structural lesion present in this condition would have to be situated in the pulmonary circulation at a point that could combine pulmonary arterial and capillary hypertension without pulmonary venous hypertension. The author's experimental work with his colleagues at Liverpool appeared to demonstrate lesions at just such a site. They exposed rats for $12 \mathrm{hr}$ in a hypobaric chamber to a subatmospheric pressure of $265 \mathrm{mmHg}$ which simulates a high altitude roughly corresponding to the summit of Mount Everest. Under these conditions multiple endothelial vesicles formed and protruded into the pulmonary capillaries (Heath, Moosavi and Smith, 1973). When seen in longitudinal sections these vesicles have an elongated shape which accommodates itself to the capillary into which it projects. These extrusions are large enough to occlude pulmonary capillaries into which they project. They arise by pedicles from localized widened areas of the fused basement membranes of the alveolar wall where there seems to be an accumulation of fluids (Heath, Moosavi and Smith, 1973). Since these endothelial vesicles form rapidly in experimental animals subjected to simulated high altitude it seems quite likely that they also occur in man in cases of high altitude pulmonary oedema.

There are certain structural features in the lung at high altitude which are unrelated to the pulmonary circulation. One of these concerns the lining epithelium of the terminal bronchioles. The author has had the opportunity recently to contrast the activity of Clara cells in the terminal bronchioles of llamas born and living in the vicinity of Rancas at an altitude of $4720 \mathrm{~m}$ in the Andes, and of a llama born and living all its life in Chester Zoo at sea level. The high altitude llama showed intense activity of the non-ciliated Clara cells which appeared as mushroom-shaped caps projecting into the bronchiolar lumen and which had extruded their caps into the bronchiole during apocrine secretion (Fig. 6). In contrast in the low-altitude llama from the Zoo the Clara cells were quiescent (Heath, Smith and Biggar, 1978). The physiological significance of such activity is not clear since the function of Clara cells is not known. There has been some suggestion that they form a secondary source of the pulmonary surfactant, dipalmitoyl lecithin (Etherton, Conning and Corrin, 1973). There has also been one report that acute exposure of rats to simulated high altitude increases the surface tension in their lungs (Castillo and Johnson, 1969). Thus it could be held that

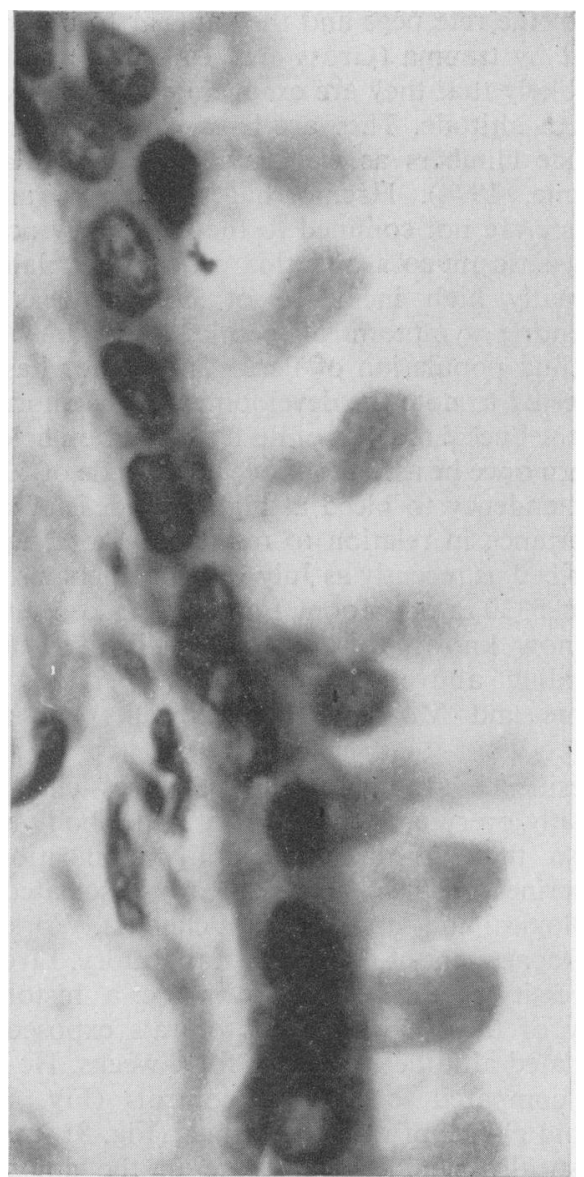

Fig. 6. Section of a terminal bronchiole from a llama born and living at Rancas at an altitude of $4270 \mathrm{~m}$ in the Peruvian Andes. Large numbers of Clara cells project into the lumen $(\mathrm{HE}, \times 1500)$.

increased Clara cell activity in llamas could be providing the added supply of pulmonary surfactant necessary for life at high altitude. This is, however, far from certain.

One of the characteristic morbid anatomical findings in subjects living at, or penetrating into, high altitude is the development of haemorrhages into various tissues. On expeditions to the Andes the author has been impressed by the haemorrhages which occur in the finger nails of healthy Quechua Indians and of patients with chronic mountain sickness (Monge's disease) (Heath and Williams, 1977). On return to sea level he was impressed to find similar haemorrhages in his own finger nails (Heath and Williams. 1978). They appear to rise in 
the nail substance itself from the capillaries in the tips of the rete pegs and they appear to be brought about by trauma (Gross and Tall, 1963), although it is likely that they are exaggerated by the hypoxia of high altitude. They are known to occur in high altitude climbers as well as in native highlanders (Rennie, 1974). Haemorrhages in those at high altitude are not confined to the skin. They occur in the gastric mucosa and this probably explains the unusually high incidence of haematemesis as a presenting symptom of peptic ulceration in the Quechua population of Peru. The author has been interested to note the development of haemorrhages into the buccal mucosa of his co-worker on field trips to Peru once he ascends above an altitude of $4000 \mathrm{~m}$. This tendency to bleed at high altitude is of special importance in relation to retinal haemorrhage first described as recently as July 1968 in 2 persons working at $5330 \mathrm{~m}$ on Mount Logan in Yukon territory but now known to occur in a third of subjects ascending above $5300 \mathrm{~m}$ (Frayser et al., 1970; Rennie and Morrissey, 1975; Shults and Swan, 1975).

Residence at high altitude induces changes in virtually every endocrine organ in the body and of course these disturbances and modifications of endocrine functions are frequently associated with histological and ultrastructural changes. Working in the Department of Pathology Laboratory, Liverpool University, Gradwell (1978) made a histological study of the thyroid glands of rats exposed to a simulated altitude of $5500 \mathrm{~m}$ for 4 weeks. He found that compared to sea-level controls (Fig. 7) the thyroid glands of the test animals (Fig. 8) showed a statistically significant increase in the amount of colloid and a statistically significant decrease in the amount of follicular epithelium. On the other hand, there was no significant change in the mean diameter of the follicles of the thyroid. These histological changes were considered to be consistent with reduced thyroid activity induced by exposure to the hypoxia of high altitude.

The endocrine testis shares in the general disturbance of the endocrine system and the testes of animals taken to high altitude show histological abnormalities. Thus the testicles of rats and rabbits taken to $4500 \mathrm{~m}$ have been reported as devoid of germinal epithelium with Sertoli cells replacing spermatogonia (Monge and Mori-Chavez, 1942). Simulated extreme altitudes of $7620 \mathrm{~m}$ lead to severe destruction of the germinal epithelium from the third day of exposure, progressing to considerable damage by the fourteenth day (Altland, 1949). There is recovery within 4 weeks of the end of such experiments. Examination of the semen in men acutely exposed to high altitude shows charac-

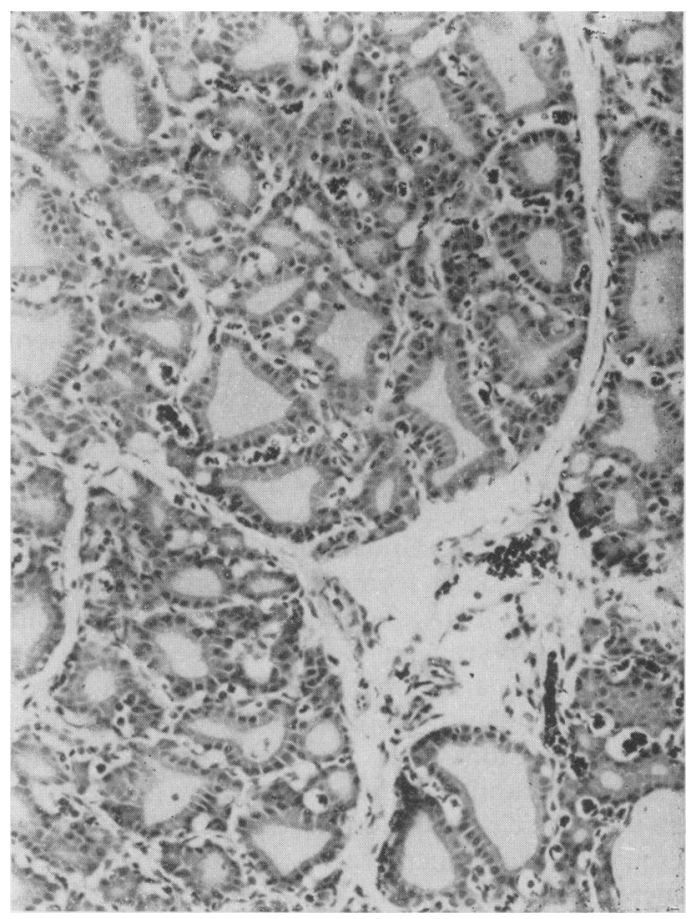

FIG. 7. A section of thyroid from a low-altitude rat. The follicles are small and are lined by cuboidal to columnar epithelium $(\mathrm{HE}, \times 150)$.

teristic changes likely to be associated with histological abnormalities similar to those described above as occurring in animals (Donayre, 1966). They include a pronounced decrease in the sperm count, an increase in abnormal forms and a decrease in motile forms. The levels of fructose increase probably owing to lack of utilization by the nonmotile spermatozoa.

At high altitude, newborns weigh less and placentas weight more than at low altitudes. Krüger and Arias-Stella (1970) studied 118 pregnancies at Lima $(150 \mathrm{~m})$ and 84 pregnancies at Rio Pallanga $(4600 \mathrm{~m})$. They found that fetuses at Rio Pallanga had a mean weight some $16 \%$ below those from Lima. The difference was more pronounced in female newborns and in multiparous pregnancies. In contrast, the average weight of the placenta was $12 \%$ greater in the high altitude cases. In this case there was no significant difference in the relation to the sex of the newborn infant. However, the placental weight in the primiparous at high altitude was $23 \%$ greater whereas in multiparous pregnancies it was only $9 \%$ greater than at low altitude. Krüger and Arias-Stella (1970) define a 'placental coefficient' as the weight of the placenta related to the weight of 


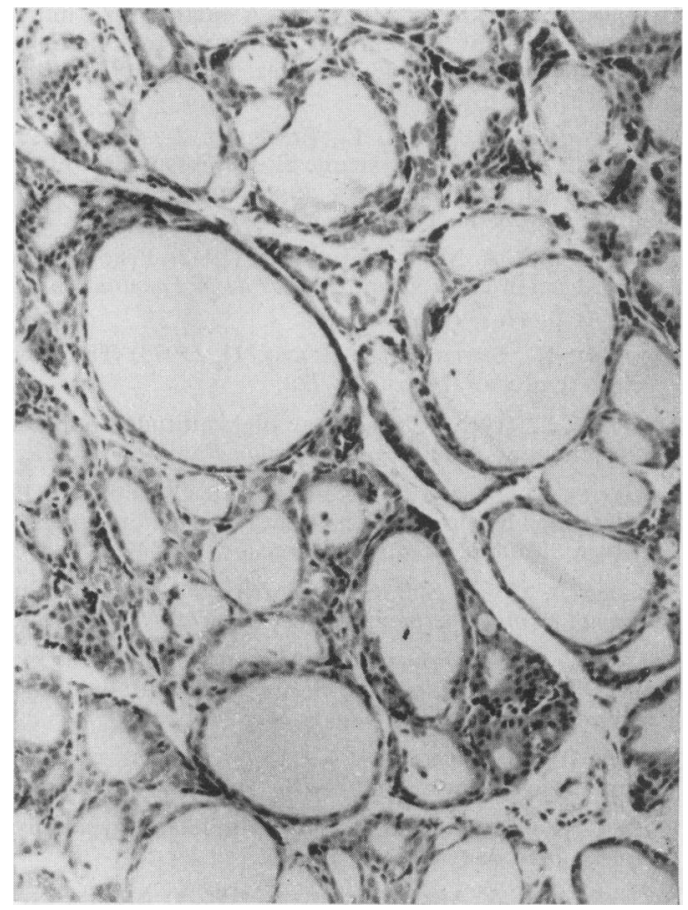

FIG. 8. A section of thyroid from a rat subjected to a simulated altitude of $5500 \mathrm{~m}$ in a decompression chamber for 4 weeks. Many of the follicles are large and lined by a flattened epithelium $(\mathrm{HE}, \times 150)$.

the newborn infant. In cases from Lima this coefficient was 0.144 but in those from Rio Pallanga it was $0 \cdot 192$, a highly significant difference. Placentas at sea level have twice as many cotyledons as those from high altitude. Furthermore, the sulci between the cotyledons of the high altitude placentas are poorly delineated.

The kidneys also show disturbances of form and function at high altitude. There is an increased excretion of protein in the urine in native highlanders and in lowlanders undergoing acclimatization to high altitude. This increase barely exceeds physiological levels but it is unequivocal (Rennie et al., 1971). It is of interest to note that there is a time lag between acute exposure to high altitude and the onset of proteinuria. This recalls the similar latent period before the onset of acute mountain sickness. At birth, children at Leadville, Colorado $(3100 \mathrm{~m})$, had renal glomeruli of normal size but disproportionate enlargement occurred in childhood compared to sea-level subjects (Naeye, 1965). The glomerular enlargement of high altitude appears to be due to a proliferation of normal glomerular elements since the 'parenchymal cell density', defined as the number of parenchymal renal cells by total glomerular area
(Naeye, 1965) is the same at high altitude as at sea level. This is precisely what is found in patients with cyanotic congenital heart disease.

This brief review has illustrated that the native highlander and the lowlander undertaking prolonged residence at high altitude develop pronounced microanatomical changes in many organs of the body. Perhaps the term 'native highlander' should be qualified as 'native highlander of the Andes' for there is much recent evidence to suggest that some of the features of natural acclimatization illustrated so well in the Quechua are not exhibited by the Sherpa of the Himalayas. The Quechuas appear to have populated the Andes for some 35000 years and this is a short time compared to the half a million years of residence that the Mongoloid peoples of Tibet have apparently sustained. It is possible that what has been described in this paper are structural features of natural acclimatization and not the condition approaching adaptation exhibited by the Sherpas.

\section{Acknowledgments}

I wish to thank Dr W. Taylor for permission to publish Figs 1, 2 and 3, Dr P. Smith for Fig. 5 and Dr E. Gradwell for Figs 7 and 8.

\section{References}

Altland, P.D. (1949) Effect of discontinuous exposure to 25,000 feet simulated altitude on growth and reproduction of the albino rat. Journal of Experimental Zoology, 110, 1.

Arias-Stella, J. (1969) Human carotid body at high altitudes. In: The 69th Program and Abstracts of the American Association of Pathologists and Bacteriologists, San Francisco.

Arias-Stella, J. \& Bustos, F. (1976) Chronic hypoxia and chemodectomas in bovines at high altitudes. Archives of Pathology, 100, 636.

Castillo, Y. \& Johnson, F.B. (1969) Pulmonary surfactant in acutely hypoxic mice. Laboratory Investigation, 21, 61.

DoNAYRE, J. (1966) Population growth and fertility at high altitude. In: Life at High Altitudes. p. 74. Scientific Publication No. 140, Pan-American Health Organization, Washington.

Edwards, C., Heath, D. \& Harris, P. (1971a) The carotid body in emphysema and left ventricular hypertrophy. Journal of Pathology, 104, 1.

Edwards, C., Heath, D. \& Harris, P. (1972) Ultrastructure of the carotid body in high-altitude guinea pigs. Journal of Pathology, 107, 131.

Edwards, C., Heath, D., Harris, P., Castillo, Y., Krüger, H. \& ARias-Stella, J. (1971b) The carotid body in animals at high altitude. Journal of Pathology, 104, 231.

Etherton, J.E., Conning, D.M. \& Corrin, B. (1973) Autoradiographical and morphological evidence for apocrine secretion of dipalmitoyl lecithin in the terminal bronchiole of mouse lung. American Journal of Anatomy, $138,11$. 
Frayser, R., Houston, C.S., Bryan, A.C., Rennie, I.D. \& GrAY, G. (1970) Retinal hemorrhage at high altitude. New England Journal of Medicine, 282, 1183.

Fred, H.L., SChmidt, A.M., Bates, T. \& Hecht, H.H. (1962) Acute pulmonary edema of altitude. Clinical and physiologic observations. Circulation, 25, 929.

Gradwell, E. (1978) Histological changes in the thyroid gland in rats on acclimatisation to simulated high altitude. Journal of Pathology, 125, 33.

Gross, N.J. \& TALL, R. (1963) Clinical significance of splinter haemorrhages. British Medical Journal, 2, 1496.

HAAS, F. \& BergofsKy, E.H. (1972) Role of the mast cell in the pulmonary pressor response to hypoxia. Journal of Clinical Investigation, 51, 3154.

Harris, P. \& HeATH, D. (1977) The Human Pulmonary Circulation, 2nd Edn, p. 452. Churchill Livingstone, Edinburgh.

Heath, D., Edwards, C. \& Harris, P. (1970) Post mortem size and structure of the human carotid body. Thorax, 25, 129.

Heath, D., Edwards, C., Winson, M. \& Smith, P. (1973a) Effects of the right ventricle, pulmonary vasculature, and carotid bodies of the rat of exposure to and recovery from simulated altitude. Thorax, 28, 24.

Heath, D., Moosavi, H. \& Smith, P. (1973b) Ultrastructure of high altitude pulmonary oedema. Thorax, 28, 694

Heath, D., Smith, P. \& BiggaR, R. (1978) Clara cells in llamas born and living at high and low altitudes. British Journal of Diseases of the Chest, (in press).

Heath, D., Smith, P., Williams, D., Harris, P., AriasStella, J., \& KRÜGER, H. (1974) The heart and pulmonary vasculature of the llama (Lama glama). Thorax, 29, 463.

Heath, D. \& Williams, D.R. (1977) Man at High Altitude, p. 71. Churchill Livingstone, Edinburgh.

Heath, D. \& Williams, D.R. (1978) Nail haemorrhages. British Heart Journal, 40, 1300.

Heath, D., Wood, E.H., Dushane, J.W. \& Edwards, J.E. (1959) The structure of the pulmonary trunk at different ages and in cases of pulmonary hypertension and pulmonary stenosis. Journal of Pathology and Bacteriology, 77, 443.

Hecht, H.H., Lange, R.L., CaRnes, W.H., Kuida, H. \& BlAKE, J.T. (1959) Brisket disease. I. General aspects of pulmonary hypertension heart disease in cattle. Transactions of Association of American Physicians, 72, 157.

KRÜGER, H. \& ARIAS-STELlA, J. (1970) The placenta and tho newborn infant at high altitudes. American Journal of Obstetrics and Gynecology, 106, 586.
LAIDLER, P. \& KAY, J.M. (1975) A quantitative morphological study of the carotid bodies of rats living at a simulated altitude of 4300 metres. Journal of Pathology. $117,183$.

Marticorena, E., Ruiz, L., Severino, J., Galvez, J. \& Peñaloza, D. (1969) Systemic blood pressure in white men born at sea level: Changes after long residence at high altitudes. American Journal of Cardiology, 23, 364.

Monge, M.C. \& Mori-Chavez, P. (1942) Fisiologia de la reproducción en la altura. Anales de la Facultad de Medicina de Lima, 25, 34.

Moosavi, H., Smith, P. \& Heath, D. (1973) The Feyrter cell in hypoxia. Thorax, 28, 729.

NAEYE, R.L. (1965) Children at high altitude: pulmonary and renal abnormalities. Circulation Research, 16, 33.

Peñaloza, D., Sime, F., Banchero, N. \& Gamboa, R. (1962) Pulmonary hypertension in healthy man born and living at high altitudes. Medicina thoracalis, 19, 449.

RENNIE, D. (1974) Splinter hemorrhages at high altitude. Journal of the American Medical Association, 228, 974.

Rennie, D., Marticorena, E., Monge, C. \& Sirotzky, L. (1971) Urinary protein excretion in high-altitude residents. Journal of Applied Physiology, 31, 257.

RENNIE, D. \& MORRISEY, J. (1975) Retinal changes in Himalayan climbers, Archives of Ophthalmology, 93, 395.

Ruiz, L. \& PeÑaloza, D. (1977) Altitude and hypertension. Proceedings. Mayo Clinic, 52, 442.

Saldaña, M. \& Arias-Stella, J. (1963a) Studies on the structure of the pulmonary trunk. I. Normal changes in the elastic configuration of the human pulmonary trunk at different ages. Circulation, 27, 1086.

Saldaña, M. \& Arias-Stella, J. (1963b) Studies on the structure of the pulmonary trunk. II. The evolution of the elastic configuration of the pulmonary trunk in people native to high altitudes. Circulation, 27, 1094.

Saldaña, M.J., Salem, L.E. \& Travezan, R. (1973) High altitude hypoxia and chemodectomas. Human Pathology, 4, 251.

Shults, W.T. \& Swan, K.C. (1975) High altitude retinopathy in mountain climbers. Archives of Ophthalmology, 39, 404.

TAYLOR, W. (1977) Pulmonary argyrophil cells at high altitude. Journal of Pathology, 122, 137.

WeIR, E.K., TuCker, A., Reeves, J.T., Will, D.H. \& Grover, R.F. (1974) The genetic factor influencing pulmonary hypertension in cattle at high altitude. Cardiovascular Research, 8, 745. 